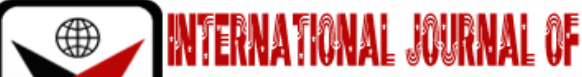

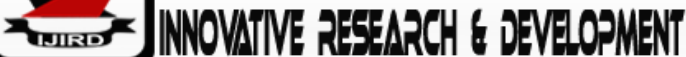

ISSN 2278-0211 (Online)

\section{Morphological Characterization of Selected Natural and Calcined Ti02 Photocatalysts Using SEM, XRD and BET}

\author{
Patrick Kimutai Tum \\ Lecturer, Department of Chemistry, University of Nairobi, Kenya \\ David K. Kariuki \\ Associate Professor, Department of Chemistry, University of Nairobi, Kenya
}

\begin{abstract}
:
The present work characterized commercial TiO2 powder photo-catalysts (P25, AV01, S7001, PC100 \& PC500) using Scanning Electron Microscopy (SEM), X-Ray Diffraction (XRD), and Brauner, Emmer and Teller (BET) techniques to determine crystalline size $(\mathrm{nm})$, particle size $(\mathrm{nm})$ and specific surface area $(\mathrm{m} 2 / \mathrm{g})$ of natural and calcined TiO2 catalyst particles. TiO2 particulate layers were prepared by deposition from aqueous TiO2suspensions $c=10 \mathrm{~g} . \mathrm{L}-1$ on degreased microscopic glass of dimensions $75 \mathrm{~mm} \times 25 \mathrm{~mm}$ calcined at $300^{\circ} \mathrm{C}$ for $2 \mathrm{hrs}$. The calcined layers were scanned to obtain cross-sectional images and reveal particle size and catalyst morphology. The results indicate a crystalline/surface area ratio as follows; [(P25=28nm $/ 50 \mathrm{~m} 2 / \mathrm{g}) ;($ AV01 $=169 \mathrm{~nm} / 10 \mathrm{~m} 2 / \mathrm{g}) ;(S 7001=9 \mathrm{~nm} / 250 \mathrm{~m} 2 / \mathrm{g})$ $;(P C 100=198 \mathrm{~nm} / 79.5 \mathrm{~m} 2 / \mathrm{g}) ;(P C 500=173.6 \mathrm{~nm} / 91.3 \mathrm{~m} 2 / \mathrm{g})]$. Particle size of AV01 powder catalyst $(100-150 \mathrm{~nm})$ was larger compared to the other catalysts., catalyst P25, PC100, PC500 and S7001 appear to have almost similar particle sizes of between (50-100 nm). Comparing the observed particle sizes using the SEM technique with those calculated using XRD, it can be concluded that these values are very similar. X-Ray Diffraction patterns indicated that the crystalline structure AV01, S7001, PC100 and PC500 comprises of pure anatase phase. Catalyst P25 catalyst powder consisted of a crystal structure $74 \%$ anatase and $26 \%$ rutile content. Crystalline sizes were calculated by Scherer formula using a special programme Analytical X'pert.PRO + high score plus. It can be concluded that smaller crystalline size favours increased surface areas. An optimum balance between surface area and crystallinity is desirable to obtain maximum semi-conductor properties since the predominant electron/hole recombination depends on relative particle size/surface area ratios.
\end{abstract}

Keywords: $\mathrm{TiO}_{2}$, catalyst morphology, calcinations, BET, SEM, XRD

\section{Introduction}

\subsection{Applications of $\mathrm{TiO}_{2}$}

Pure titanium dioxide is a bright white powder that is used as a pigment in various industrial and consumer products. It is produced in two main grades i.e., pigment and nano-scale (Kulkarniet al., 2015). Pure titanium dioxide is extracted from ilmenite ores (Cordero-Arias et al., 2013). These ores are the principal raw materials used in the manufacture of titanium dioxide pigments (Ajmal et al., 2014; Woan et al., 2009). The pigment is produced either by the sulphate process, which uses sulfuric acid or the chloride process, which uses chlorine.Pigment grade $\mathrm{TiO}_{2}$ is $\mathrm{used}$ in applications that require high opacity and brightness. Pigment grade $\mathrm{TiO}_{2}$ finds application in paints and coatings, plastics, pharmaceuticals, adhesives and rubber; cosmetics; food contact materials and ingredients (Umebayashi et al., 2003). Nano-scale grade $\mathrm{TiO}_{2}$ used in specialty applications i.e., sunscreen nanoscale $\mathrm{TiO}_{2}$ becomes transparent to visible light and effectively absorbing UV light. Nano $\mathrm{TiO}_{2}$ does not reflect visible light but absorbs UV light. $\mathrm{Nano}_{-} \mathrm{Scale}^{\mathrm{TiO}} \mathrm{O}_{2}$ is used as a catalyst for industrial applications e.g., wastewater treatment, remove harmful exhaust gas emissions in automobile, remove nitrous oxides in power stations (Cabanas-Polo\& Boccaccini, 2015).

\subsection{Titanium Dioxide as a Semi-Conductor}

Semi-conductors e.g., $\mathrm{TiO}_{2}$ have their valence and conduction bands on different energy levels. Whenever UV light in the form of a photon with energy equal or greater than band gap energy, $\mathrm{E} g$, falls on the surface of the semi-conductor it leads to the formation of electron/hole $\left(\mathrm{e}^{-} / \mathrm{h}^{+}\right)$pairs with free electrons produced in the empty conduction band leaving behind an electron vacancy or hole in the valence band (Tum \& Kariuki, 2020). The formation of holes allows adsorbed water to be oxidized to strong *OHradicals whose strong oxidative species (2.8 V vs. SHE) and are able to oxidize organic molecules (Fujishima et al., 2008). These organic intermediates are further oxidized by molecular oxygen or *0Hradicals and fully mineralized to carbon dioxide and water. To complete the reaction, electrons react with the dissolved oxygen on 
the $\mathrm{TiO}_{2}$ surface to form super oxide radicals. If the degradation is performed in acidic media the superoxide radical anion protonates to give hydroperoxide radical. The light is defined by its energy, $E$ and wavelength, $\lambda$, as illustrated in equation 1 below:-

$E=\frac{h c}{\lambda}$

h Planck's constant

c speed of light

E energy

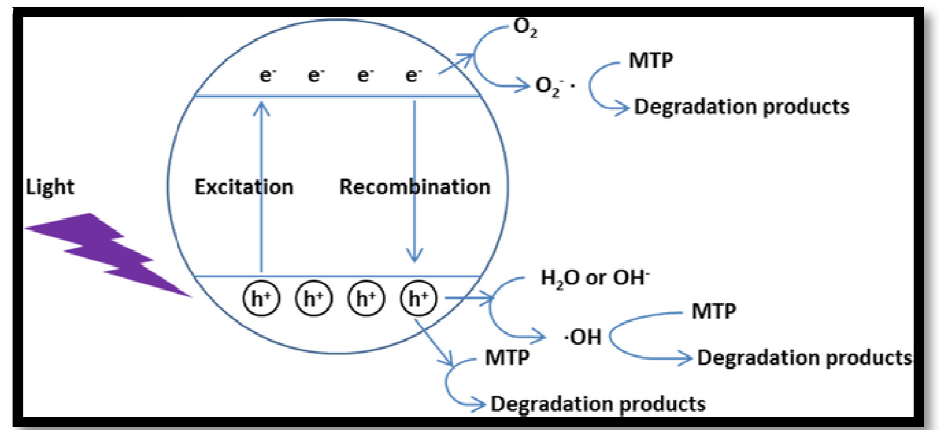

Figure 1: Scheme of Photocatalysis in Aqueous Solutions Containing Oxidative and Reductive Species

Carp et al., 2004

The equations below indicate the reactions that take place:

$$
\begin{aligned}
& \mathrm{TiO}_{2}+\mathrm{hv} \rightarrow \underset{-}{\mathrm{e}_{C B}+\mathrm{h}_{V B}^{+}} \\
& \mathrm{O}_{2}+\mathrm{e}_{C B}^{-} \rightarrow \mathrm{O}_{2}^{-} \\
& \mathrm{H}_{2} \mathrm{O}+\mathrm{h}_{v B}^{+} \rightarrow \mathrm{OH}^{\bullet}+\mathrm{H}^{+}
\end{aligned}
$$

The hydroxyl radicals $\left({ }^{*} \mathrm{OH}\right)$ and superoxide radical's anions $\left(\mathrm{O}_{2}^{\cdot-}\right)$ are the primary oxidizing species in the photocatalytic processes (Chiouet al., 2008; Dixit et al., 2010).

\subsection{Structural and Morphological Properties of $\mathrm{TiO}_{2}$}

Crystallite transformations obtained by high-temperature calcinations, crystallite growth and serious sintering are observed with increasing temperature of calcinations, leading to drastic decrease in catalyst surface area. Photocatalytic activity influences catalyst surface area, but rather on the availability of active sites where oxidative reactions can take place (Chiou et al., 2008).The amount of the surface-adsorbed water and hydroxyl groups is related to the crystallite form and surface area. Anatase phase of $\mathrm{TiO}_{2}$ is more active than rutile in adsorbing water and forming hydroxyl groups and this is probably the main reason for higher photocatalytic efficiency of anatase compared to rutile (Yu \& Wang, 2010; Cernigoj et al., 2006).A large surface area can be determining factor in certain photodegradation reactions, as a large amount of adsorbed molecules promotes the reaction rate. However, powders with large surface area are usually associated with low crystallinity and large number of crystalline defects, which favour the recombination of electrons and holes leading to a poor photoactivity. A balance between surface area and crystallinity must be found in order to obtain the highest photoactivity (Muniz et al., 2011). Particle size is an important parameter for photocatalytic efficiency, since the predominant way of electron/hole recombination may be different depending on the particle size (Carp et al., 2004). The nanometer-size range, physical and chemical properties of particles including semiconductors are modified compared with bulk. Small variations in particle diameters lead to great modifications in the surface/bulk ratio, thus modifying the significance of volume and surface electron-hole recombination. When the crystallite dimension of a semiconductor particle falls below a critical radius of approximately $10 \mathrm{~nm}$, the charge carriers appearto behave quantum mechanically (Cernigoj et al., 2006; Carp et al., 2004)).

\section{4. $\mathrm{TiO}_{2}$ Particle Size and Surface Morphology}

$\mathrm{TiO}_{2}$ particle sizes are calculated by XRD using the Scherer's equation $\mathrm{l}=k \lambda / \beta \cos \theta$ (Cernigoj et al.,2006; Krysaet al., 2006). Particle size may also be influenced by other factors e.g., experiments show that slightly larger anatase grains of films deposited on bare glass substrates maybe a consequence of higher concentration of $\mathrm{Na}^{+}$that diffuses from the substrates. $\mathrm{Na}^{+}$ions have been found to act as a flux material for crystal growth. Generally smaller catalyst particles favour a larger inner surface area (Sang-Hun et al., 2002; Muniz et al., 2011). The combination of surface area and particle size are important determining factors in photodegradation reactions because large surface areas lead to effective contact with organic pollutant molecules and this promotes higher reaction rates because more active sites are available for reactions to take place (Cernigoj et al., 2006; Sarah et al., 2010). Despite smaller crystals having larger inner surface areas, smaller catalyst particles can also promote the recombination of photogenerated electrons and holes, which in turn leads to poor photoactivity. A balance between surface area and particle size must be found in order to find the optimum photocatalytic activity (Narayan \& Raturi, 2012). It has been reported in literature that $\mathrm{TiO}_{2}$ particle size of $10 \mathrm{~nm}$ increased 
photocatalytic oxidation rates. Surface area measurements are usually calculated using BET method.X-ray diffraction (XRD) determines catalyst particle size (Yousefipouraet al., 2013). Another technique used to estimate crystal is SEM technique method from which crystal sizes can be estimated by observing the images.

\subsection{Objectives}

The main objective of the study was to characterize natural and calcined $\mathrm{TiO}_{2}$ semi-conductor photocatalyst by determining surface area, crystalline and particle size.

\section{Experimental}

\subsection{Preparation of $\mathrm{TiO}_{2}$ Particulate Layers for Annealing}

Particulate layers coated with $\mathrm{TiO}_{2}$ were prepared by deposition from aqueous $\mathrm{TiO}_{2}$ suspension from four natural $\mathrm{TiO}_{2}$ powder (Tum \& Kariuki, 2020). Suspensionconcentrations of 10 g. $\mathrm{L}^{-1}$ of both commercial and calcined $\mathrm{TiO}_{2}$ powders were prepared. The catalyst suspensions were thereafter treated to ultra-sound decibels to break down agglomerates present and make the suspension uniform. A volume of $3.75 \mathrm{~mL}$ of the catalyst suspension was deposited on the microscopic glass substrates of dimensions $75 \mathrm{~mm} \times 25 \mathrm{~mm}$ and left to dry at room ambient temperature i.e., a surface density of $0.5 \mathrm{mg} / \mathrm{cm}^{2}$ of catalyst was immobilized on the glass slide (Krysa et al.,2006). The resulting $\mathrm{TiO}_{2}$ particulate films were then calcined at $300^{\circ} \mathrm{C}$ for 2 hours after which the final area covered by the photocatalyst was reduced to $25 \mathrm{~mm}$ $\times 35 \mathrm{~mm}$ covering geometrical area of $8.75 \mathrm{~cm}^{2}$ (Tum \& Oduor, 2014; Tum \& Kariuki, 2020).

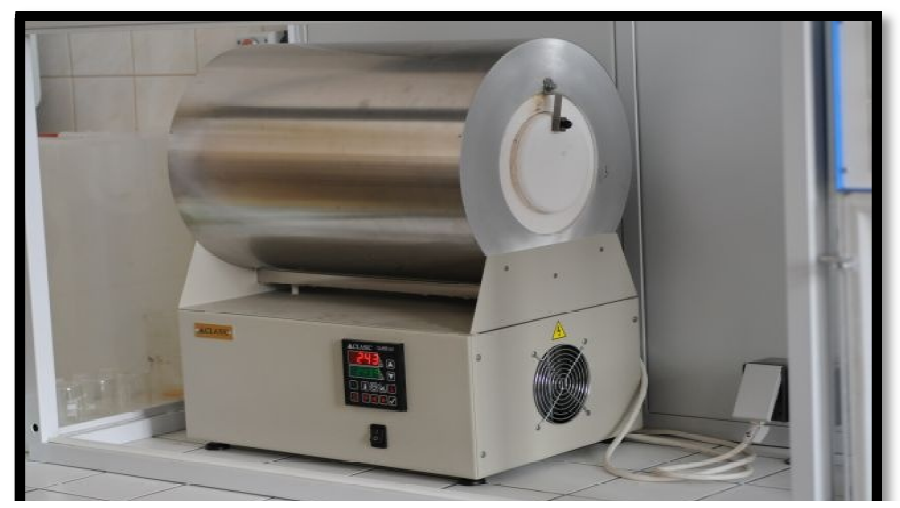

Figure 2: Furnace Used to Calcine $\mathrm{Tio}_{2}$ Particulate Layers for SEM

Analysis (Tum \&Oduor, 2014)

\subsection{Characterization of Photocatalyst Using SEM, XRD and BET Analytical Techniques}

\subsubsection{Scanning Electron Microscopy (Crystalline Size)}

A Tescan VEGA3 Scanning Electron Microscope equipped with a field emission source was preferred over regular SEM with Lanthanum hexaboride filament as a high voltage source for morphological characterization. This is because of its high resolution and brightness at low accelerating voltages that allows for clearer images(Barneset al., 2010) Prior to SEM, the samples were first mounted on an aluminum stub using a double-sided carbon tape, and then coated with a thin layer of 10-30 nm composed of 60:40 gold-palladium alloy by means of vacuum sputtering coating using a Denton Desk 1 Sputter-Coater under a 70-motor vacuum. Other conditions included: (SEM HV-20.0 kV, view field- $6.36 \mu \mathrm{m}$ and SEM mag$30.0 \mathrm{kx})$.

- Two sample of each $\mathrm{TiO}_{2}$ powder were inscribed for identification

- The samples were dried at an oven $60^{\circ} \mathrm{C}$ for 3 hours

- The samples were loaded into the SEM and blown with inert nitrogen gas to protect any further oxidation reactions.

- The acceleration voltage was set at $20 \mathrm{KV}$, lowest magnification (30X) and TV mode.

- The coarse focus was switched on and the focus knob adjusted to a safe working distance of $14 \mathrm{~mm}$.

- The focus was switched to slow scan mode and magnification increased. The samples stage was brought up slowly by pressing z-axis UP key. The variable button was opened up to open a small variable window on the screen. The image was focused within the small screen using outer focus ring and inner focus ring until indicator light reaches the middle.

- The image was previewed and adjusted to contrast and the image set-up window closed. The image acquire icon was clicked to record the image formed and the image saved (Yousifet al., 2010; Kariuki \& Tum, 2019; Sarah et al., 2010).

\subsubsection{X-Ray Diffraction (Particle Size)}

Particle sizes are calculated by XRD using the Scherer's equation;

$l=k \lambda / \beta \cos \theta$

(Yousefipouraet al., 2013)

$\lambda$ is the wavelength of rays, 
$\mathrm{k}$ is a constant taken to be 0,9 (assuming no crystal distortions in the lattice),

$\beta$ is the width at half maximum of the radians corrected for the instrumental broadening and

$\theta$ is the diffraction angle in degrees.

- $\quad$ Scan parameters: start and end $2 q$ limits $0-130-2 q$

- $\quad$ Step size $0.5-0.1-2 q$

- $\quad$ Step time (1 sec)

- Start scan

- When scan was completed the file was saved

\subsubsection{Brunauer Emmett Teller (Specific Surface Area)}

The BET surface area was measured through a multipoint method utilizing adsorption data in the relative pressure (P/Po) in the range 0.005-0.3 using nitrogen (99.99\%) physico-sorption at $200^{\circ} \mathrm{C}$ ( Lin et al., 2008; Sarah, 2010).

- The system used liquid nitrogen in a $500 \mathrm{~mL}$ Dewar flask placed on the stage of the instrument.

- $\mathrm{TiO}_{2}$ were heated at $150^{\circ} \mathrm{C}$ for 2 hours to remove adsorbed water

- The resolution of the images formed were set at 80 seconds

\section{Results and Discussions}

3.1. Morphological Characterization - Natural and Calcined Tio 2 photocatalyts

Table 1 below indicates the results of $\mathrm{TiO}_{2}$ powder analysis using SEM, XRD and BET.

\begin{tabular}{|c|c|c|c|}
\hline TiO $_{2}$ & $\begin{array}{c}\text { Particle Size(nm) } \\
\text { (SEM) }\end{array}$ & $\begin{array}{c}\text { Crystalline Size(nm) } \\
\text { (XRD) }\end{array}$ & $\begin{array}{c}\text { Surface Area(m } \\
\text { (X) } / \mathbf{g}^{\prime} \\
\text { (BET) }\end{array}$ \\
\hline P25 & 50 & 28 & 50 \\
\hline AV01 & $100-150$ & 169 & 10 \\
\hline S7001 & $50-100$ & 9 & 250 \\
\hline PC 100 & $50-100$ & 198 & 79.5 \\
\hline PC 500 & $50-100$ & 173.6 & 91.3 \\
\hline
\end{tabular}

Table 1: Natural and Calcined Tio 2 Morphology (Particle Size, Crystalline Size \& Surface Area)

The findings shown in figure 1 indicate that the photocatalyst AV01 has the biggest particle size (100-150 nm) and smallest specific surface area $\left(10 \mathrm{~m}^{2} / \mathrm{g}\right)$. Photocatalyst $\mathrm{S} 7001$ possesses the smallest crystalline size (9 nm) and has the highest surface specific area (250 $\left.\mathrm{m}^{2} / \mathrm{g}\right)$. The particle size of catalysts S7001, PC 100 and PC 500 are quite similar (50-100 $\mathrm{nm}$ ). Comparing calculated crystalline sizes from for catalyst AV01, with particle size obtained from SEM, we can conclude that individual crystals of the catalyst are visible. The resulting particle sizes (amorphous portion of catalyst) were expressed in nm using the SEM images and the BET \& XRD techniques were used to determine the surface areas and crystalline sizes (crystalline portion of catalyst) respectively.

\subsection{X-Ray Diffraction Patterns - Natural Tio 2 powder Catalysts}

\subsubsection{PC $100 \mathrm{TiO}_{2}$ Powder}

Table 2 below shows the phase composition for PC 100 catalyst.

\begin{tabular}{|c|c|c|c|c|}
\hline Ref. Code & Score & Compound Name & Chemical Formula & SemiQuant [\%] \\
\hline 01-071-1169 & 80 & Anatase & $\mathrm{TiO}_{2}$ & 100 \\
\hline
\end{tabular}

Table 2: PC 100 Powder Catalyst Structure

The results in Table 2 show that the catalyst structure consists purely of anatase phase.

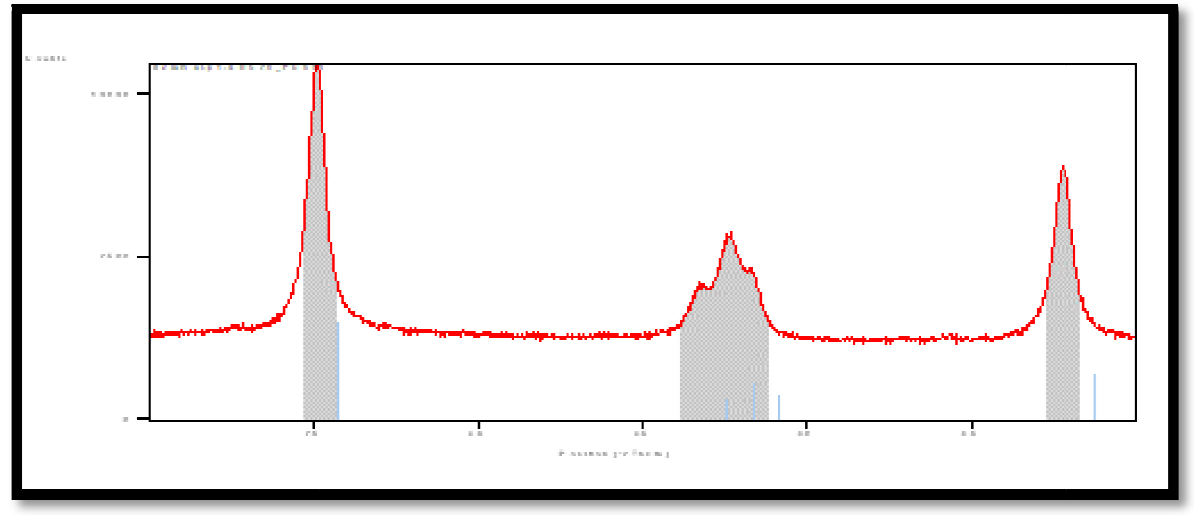

Figure 3: Diffractogram of Powder Catalyst PC 100 


\subsubsection{PC $500 \mathrm{TiO}_{2}$ Powder}

Table 3 below indicates the phase composition for PC 500 catalyst.

\begin{tabular}{|c|c|c|c|c|}
\hline Ref. Code & Score & Compound Name & Chemical Formula & SemiQuant [\%] \\
\hline $01-071-1169$ & 70 & Anatase & $\mathrm{TiO}_{2}$ & 100 \\
\hline \multicolumn{7}{|c|}{ Table 3: PC 500 Powder Catalyst Crystal Structure }
\end{tabular}

From table3 we conclude that PC500 catalyst structure purely consists of anatase phase

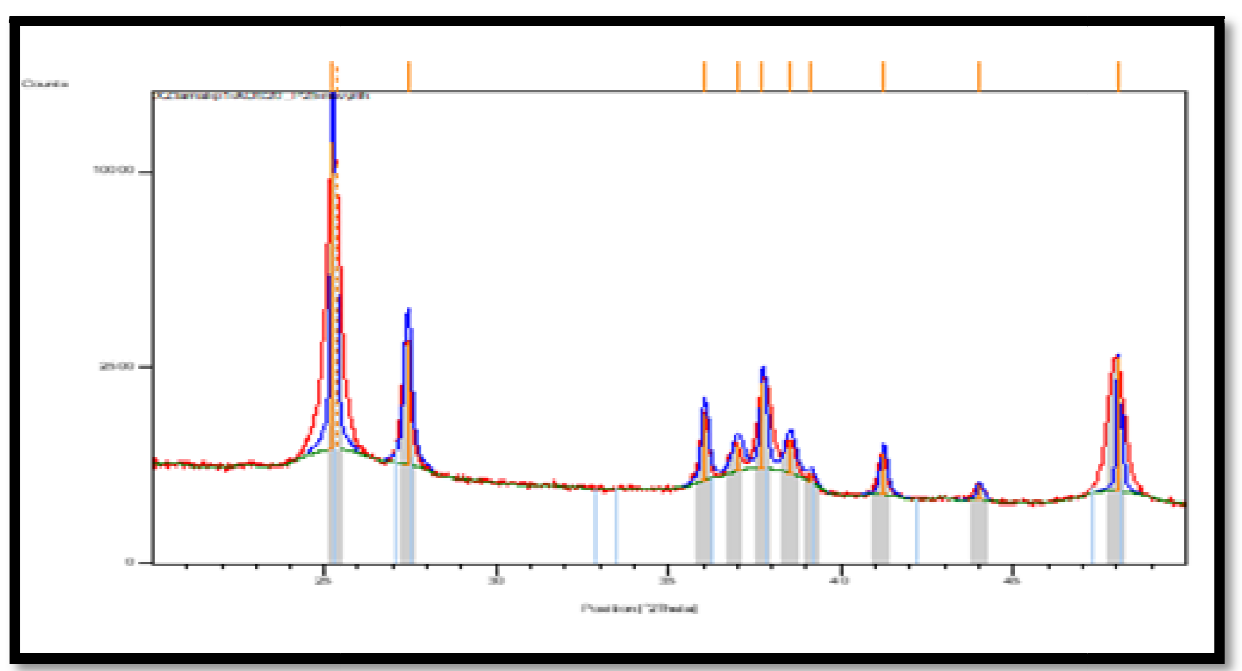

Figure 4: Diffractogram of Powder Catalyst PC 500

\subsection{3. $\mathrm{P} 25 \mathrm{TiO}_{2}$ Powder}

Table 4 below indicates the phase composition for P 25 catalyst.

\begin{tabular}{|c|c|c|c|c|}
\hline Ref. Code & Score & Compound Name & Chemical Formula & SemiQuant [\%] \\
\hline $01-071-1167$ & 75 & Anatase & $\mathrm{TiO}_{2}$ & 74 \\
\hline $01-076-0318$ & 78 & Rutile, syn & $\mathrm{TiO}_{2}$ & 26 \\
\hline
\end{tabular}

Table 4: P25 Powder Catalyst Crystal Structure

From Table 4, we conclude that catalyst P25 has a crystal structure $74 \%$ anatase and $26 \%$ rutile.

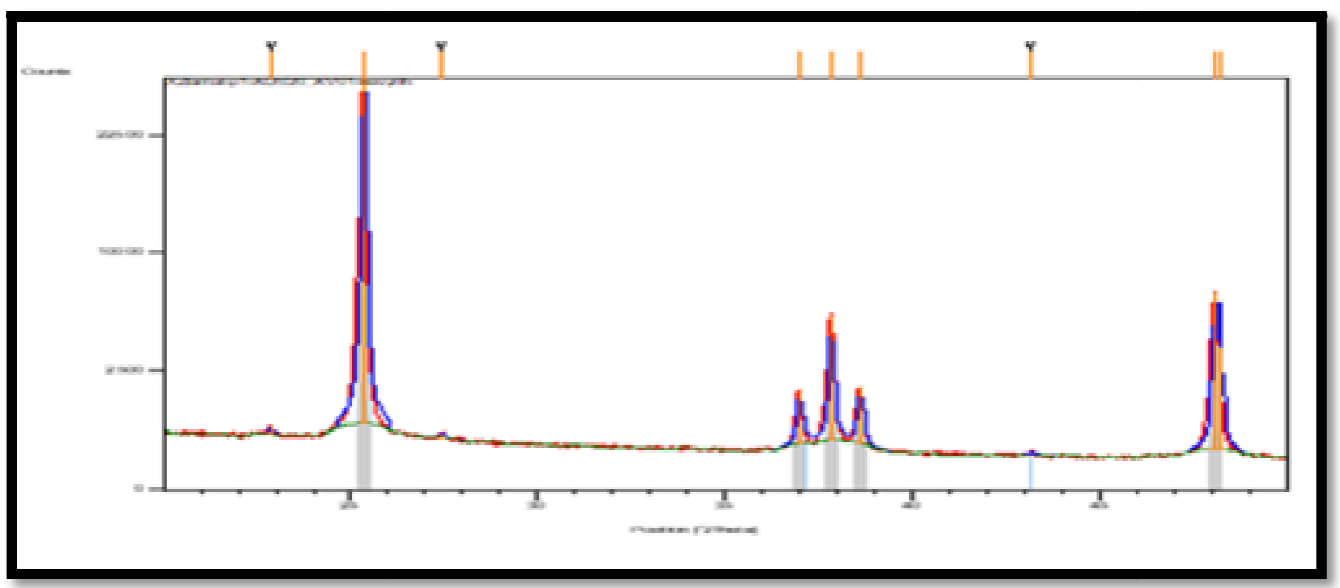

Figure 5: Diffractogram of Powder Catalyst P25

$\underline{\text { 3.2.4. AV01 } \mathrm{TiO}_{2}} \underline{\text { Powder }}$

Table 5 below indicates the phase composition for AV01 catalyst.

\begin{tabular}{|c|c|c|c|c|}
\hline Ref. Code & Score & Compound Name & Chemical Formula & SemiQuant [\%] \\
\hline 01-084-1286 & 77 & Anatase, syn & $\mathrm{TiO}_{2}$ & 100 \\
\hline \multicolumn{5}{c}{ Table 5: AV01 Powder Catalyst Crystal Structure }
\end{tabular}

From Table 5, we conclude that catalyst AV01 has a crystal structure 100\% anatase. 


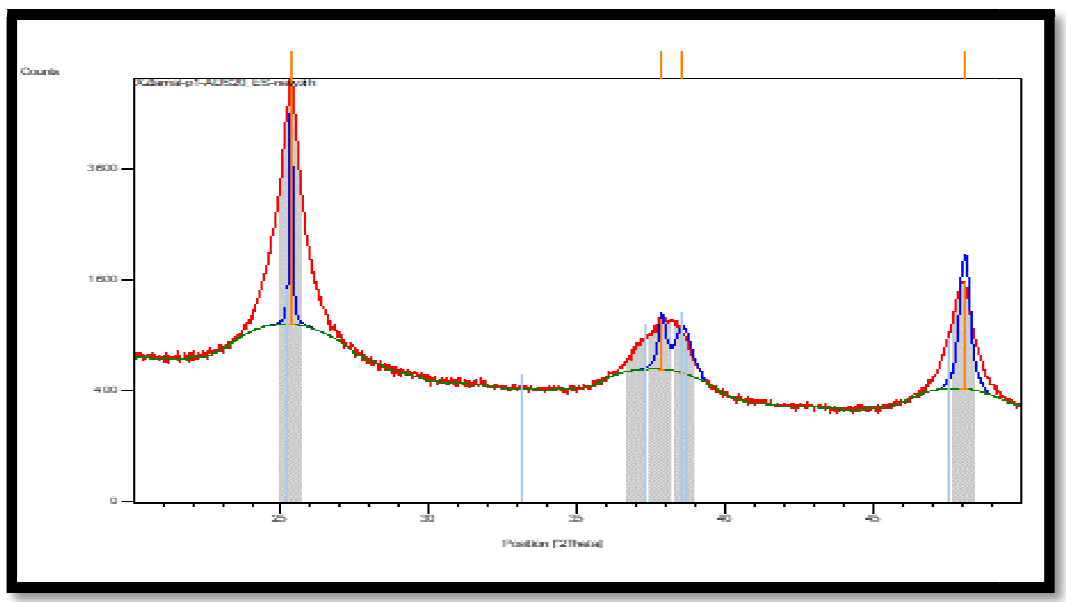

Figure 6: Diffractogram of Powder Catalyst AV01

Scanning Electron Microscopy $(\mathrm{SEM})-$ annealed $\mathrm{TiO}_{2}$ powder catalysts immobilized on microscopic glass $\mathrm{m}_{\mathrm{TiO} 2}=$ $0.5 \mathrm{mg} / \mathrm{cm}^{2}$ at various resolutions $(5 \mu \mathrm{m} \& 500 \mu \mathrm{m})$.

The SEM images shown below indicate the catalyst morphology of the calcined $\mathrm{TiO}_{2}$ photocatalysts; (AV01, P25, S7001, PC100\&PC500) at two distinct resolutions.

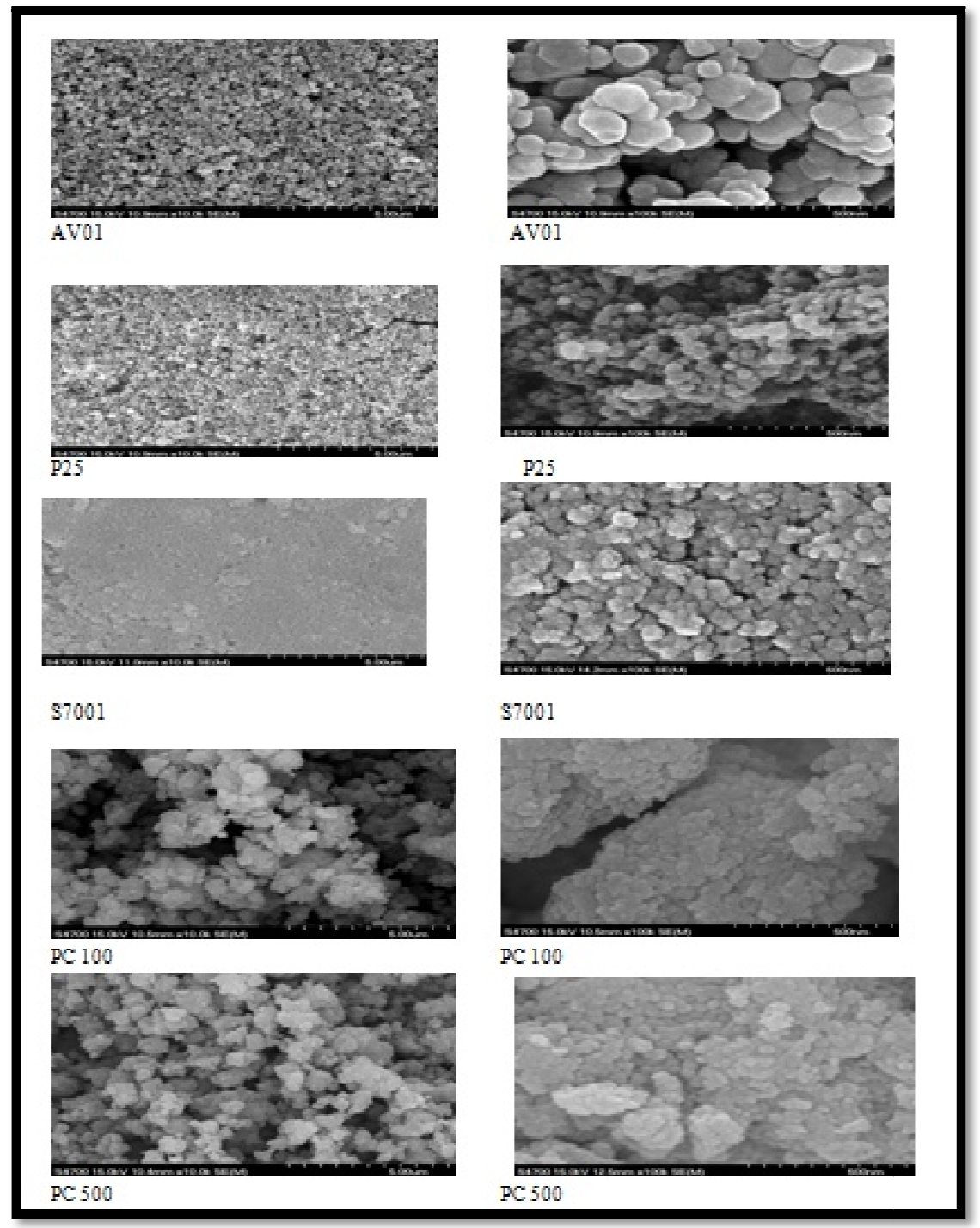

Figure 7: SEMImages of Calcined Tio $_{2}$ particulate Layers

The images calcined $\mathrm{TiO}_{2}$ photocatalysts taken using SEM technique, characterizes the catalyst particle sizes and hence depicting catalyst morphology. The particle sizes of catalyst AV01 (100-150 nm) are larger compared to the other catalysts. Catalysts PC100, PC500 and S7001 appear to have almost identical particle sizes of between (50-100 nm). Characterization of catalyst powder was also performed using XRD and BET techniques. Except for powder P25 all others consist of pure anatase phase as depicted by the Diffractograms in figure 4 - figure 6 and Table 1,2,3,4 \&5. 
A large surface area can be determining factor in certain photodegradation reactions, as a large amount of adsorbed molecules promotes the reaction rate. However, powders with large surface area are usually associated with low crystallinity and large number of crystalline defects, which favour the recombination of electrons and holes leading to a poor photoactivity (Cernigoj et al., 2006). A balance between surface area and crystallinity must be found in order to obtain the highest photoactivity (Lin et al., 2008; Seo et al., 2017)). Particle size is an important parameter for photocatalytic efficiency. Anatase phase of $\mathrm{TiO}_{2}$ is more active than rutile in adsorbing water and forming hydroxyl groups and this is probably the main reason of higher photocatalytic efficiency of anatase compared to rutile.

\section{Conclusions}

$\mathrm{TiO}_{2}$ powder photocatalysts structure may consist purely of anatase phase or comprise additionally of rutile phase. Inthis study the P25 $\mathrm{TiO}_{2}$ photocatalyst consisted of mainly anatase and rutile phases. The AV01, S7001, PC100 \&PC500 comprised purely of anatase phase. Smaller $\mathrm{TiO}_{2}$ crystalline size favours increased surface areas of individual catalyst powders. The SEM images indicate individual crystals of the catalysts.

\section{References}

i. Ajmal, A; Majeed, I; Malik, R N; Idriss, H \& Nadeem, M A. (2014). Principles and mechanisms of photocatalytic dye degradation on $\mathrm{TiO}_{2}$ based photocatalysts: A comparative overview. Rsc Advances, 4,(70), pp.37003-37026.

ii. Barnes, R.J., Riba, O., Gardner, M.N., Scott, T.B., Jackman, S.A \&Thompson, I.P. (2010). Optimization of nanoscale nickel/iron particles for the reduction of high concentration chlorinated aliphatic hydrocarbon solutions. Chemosphere, 79, pp.448-454.

iii. Carp, O., Huisman, C L \& Reller, A. (2004). Photoinduced reactivity of titanium dioxide. Progress in solid state chemistry, 32, (1), pp.33-177.

iv. Chiou, C.H., Wu, C.Y \& Juang, R.S. (2008). Influence of operating parameters on photocatalytic

v. Degradation of phenol in UV/TiO 2 process. Chem Eng J., 139, pp.322-329.

vi. Dixit, A., Mungray, A.K. \&Chakraborty, M. (2010). Photochemical Oxidation of Phenol andChlorophenol by UV $/ \mathrm{H}_{2} \mathrm{O}_{2} / \mathrm{TiO}_{2}$ Process: A Kinetic Study. Int J Chem Eng Appl., 1, pp.247-256.

vii. Krýsa, J; Waldner, G; Měšt’ánková, H; Jirkovský, J\&Grabner, G. (2006). Photocatalytic degradation ofmodel organic pollutants on an immobilized particulate $\mathrm{TiO}_{2}$ layer: Roles of adsorption processes and mechanistic complexity. Appl Catal Environ.64, pp.290-301.

viii. Lin, C.F; Wu, C.H \&Onn, Z.N (2008). Degradation of 4-chlorophenol in $\mathrm{TiO}_{2}, \mathrm{WO}_{3}, \mathrm{SnO}_{2}, \mathrm{TiO}_{2} / \mathrm{WO}_{3} \mathrm{and}_{\mathrm{TiO}_{2}} / \mathrm{SnO}_{2}$ systems. J Hazard Mater., 154, pp.1033-1039.

ix. Seo, J.K., Ki-Joon, J., Young-Kwon, P., Sangmin, J., Heon, L \& Sang-Chul, J. (2017). Improving removal of 4chlorophenol using a $\mathrm{TiO}_{2}$ photocatalytic system with microwave and ultraviolet tradition. Catalysis Today. 293-294, pp. 15-22.

x. Tum, P.K \& Kariuki, D.K. (2020). Photocatalytic Degradation of 4-Chlorophenol by Titanium Dioxide: Role of Annealing Temperature and Morphology. J. Appl. Sci. Environ. Manage. 24 (1), pp.5-12.

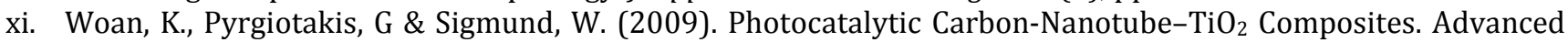
Materials, 21(21), pp. 2233-2239.

xii. Umebayashi, T., Yamaki, T., Tanaka, S., \& Asai, K. (2003). Visible Light-Induced Degradation of Methylene Blue on S-doped $\mathrm{TiO}_{2}$. Chemistry Letters, 32(4), pp. 330-331.

xiii. Kariuki, D.K \&Tum, P.K. (2019). Effect of Sonication Pre-treatment of $\mathrm{TiO}_{2}$ Catalyst for Photo-Degradation of Acid Orange 7 Azo Dye. International Journal of Chemistry; 11, (2), pp.22-30.

xiv. Cabanas-Polo, S \&Boccaccini, A. (2015).Electrophoretic deposition of nanoscale $\mathrm{TiO}_{2}$ : technology and applications. Journal of the European Ceramic Society, 7, pp. 38-45.

xv. Černigoj, U., Štangar, U. L., Trebše, P., Krašovec, U. O., \& Gross, S. (2006). Thin Solid Films, 495, pp. 327-332.

xvi. Cordero-Arias, L., Cabanas-Polo, S., Gao, H. X., Gilabert, J., Sanchez, E., Roether, J. A. \&Boccaccini, A. R. (2013). .Electrophoretic deposition of nanostructured- $\mathrm{TiO}_{2} /$ chitosan composite coatings on stainless steel. $R S C$ Adv., 3,pp.11247-11254.

xvii. Fujishima, A., Zhang, X. T., \& Tryk, D. A. (2008). $\mathrm{TiO}_{2}$ photocatalysis and related surface phenomena. Surf Sci Rep., 63, pp. 515-582.

xviii. Kulkarni, M., Mazare, A., Gongadze, E., Perutkova, Š. Kralj-Iglič, V., Milošev, I\&Mozetič, M. (2015). Titanium nanostructures for biomedical applications. Nanotechnol.,26, 062002.

xix. Narayan M. R., \& Raturi, A. (2012). Deposition and characterization of titanium dioxide films formed by electrophoretic deposition. International Journal of Materials Engineering Innovation, 3(1), pp.17-31.

xx. Yousefipoura, K., Akbari, A., \&Bayati, M. R. (2013). The effect of EEMAOprocessing on surface mechanical properties of the $\mathrm{TiO}_{2}-\mathrm{ZrO}_{2}$ nanostructured composite coatings. Ceramics Int., 39,pp.7809-7815.

xxi. Tum, P.K\& Oduor, F.D.O. (2014). Effects of Calcination Temperature on Titanium dioxide Photocatalyst Morphology.Journal of Kenya Chemical Society, 8(1), pp.26-32.

xxii. Sang-Hun, J., Bong-Soo, K \&Byung-Teak, L. (2002).'Structural and Optical Properties of $\mathrm{TiO}_{2}$ Films Prepared Using Reactive RF Magnetron Sputtering', Journal of the Korean Physical Society, 41, pp. 67-72.

xxiii. Muniz, E.C., Goes, M.S., Silva, J., Varela, J.A., Joanni, E., Parra, R \&Bueno, P.R. (2011).'Synthesis and characterization of mesoporous $\mathrm{TiO}_{2}$ nanostructured films prepared by a modified sol-gel method for application in dye solar cells', Ceramics International,37, pp. 1017-1024. 
xxiv. Yousif, A.A., Sarmad, S \& Al-Obaidi, S. (2010).'Study of annealing effect on the some physical properties of nanostructured $\mathrm{TiO}_{2}$ films by PLD', University of Al-Mustansiriyah, Baghdad, pp.1-22.

xxv. Sarah, M.S.P., Musa, M.Z., Asiah, M.N \&Rusop, M. 'Electrical conductivity characteristics of $\mathrm{TiO}_{2}$ thin film,' in International Conference on Electronic Devices, Systems and Applications (ICEDSA 2010), IEEE Xplore, pp.361-364.

xxvi. Yu, J.G\&Wang, B. (2010). Effect of calcination temperature on morphology and photo electrochemical properties of anodized titanium dioxide nanotube arrays,Appl. Catal. B: Environ., 94, pp.295-30 